\title{
Keloid treatment: what will be the right choice?
}

\author{
You-Bin Wang \\ Department of Plastic Surgery, Peking Union Medical College Hospital, Beijing 100730, China.
}

Correspondence to: Dr. You-Bin Wang, Department of Plastic Surgery, Peking Union Medical College Hospital, Beijing 100730, China. E-mail: wybenz@sina.com

How to cite this article: Wang YB. Keloid treatment: what will be the right choice? Plast Aesthet Res 2017;4:106-7.

Article history: Received: 10-06-2017 Accepted: 14-06-2017 Published: 17-07-2017

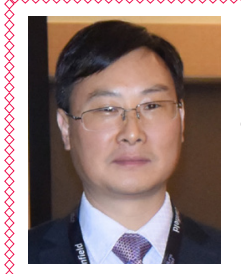

Dr. You-Bin Wang is an outstanding Professor in the Department of Plastic Surgery at Peking Union Medical College Hospital. He is famous in keloid treatment and study. He has invented many new surgical methods in keloid treatment and has published many articles in this field. He is also good at cleft lip surgery, nose reconstructive surgery and breast reconstruction.

I do not know the meaning of "disease without satisfactory treatment method", but I know the principle the doctor should obey when he faces such patients. That is he should choose the most effective method for the patients, considering not the interest of himself, but the benefit of the patients, not the treatment method he can offer, but the method the patients need. Unfortunately, such principles are not followed sometimes. Patients in plight are often manipulated by evil hand and then drop into despair circumstance. They become suspicious of every doctor in this field in the end. The development in this field is then blocked forever.

Keloid is one of such disease. The dilemma of its treatment fosters many treatment methods such as surgical therapy, cryosurgery, steroid injection, 5-flourouracil injection, radiation therapy, laser therapy, and so on, even plaster made of herbs and combination usage of them. Which method is the most effective? Which method should we choose? These questions have been partially answered in literatures. One can find some of these answers with just one browse. Articles in this keloid treatment series add more tips to the answer database. They covered wide knowledge range of keloid treatment from surgical method to adjunctive radiotherapy and post surgery scar rehabilitation. I hope that these tips can bring the patient some delightful tip. I also hope more tips will be added in this database in the future.

It is not very easy to make a decision for keloid patient, especially when one faces a patient with suspicion. It is also easy to make a decision for keloid patient, especially when one make the decision in favor of the patient. Maybe you can not confirm the choice is right or not in the long ran at first, but the patient will tell you the answer in the future. More patients will come for

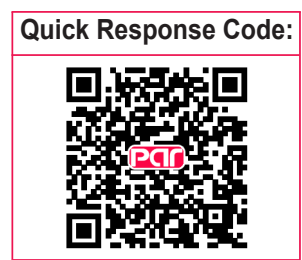


your help if your choice is right. They will never come back otherwise. You choose for the patient, the patient will choose you in the future. No absolute truth is there in the field of keloid treatment, but there is absolute truth in keloid patient treatment. Try to find a right method from the literature database and make the right choice for keloid patient. Summarize the results and add more tips for the literature database. The patient will benefit from what you have done.

\section{Authors' contributions}

Y.B. Wang contributed solely to the paper.
Financial support and sponsorship None.

\section{Conflicts of interest}

There are no conflicts of interest.

\section{Patient consent}

Not applicable.

\section{Ethics approval}

Not applicable. 